\title{
Inverse Association of Coronary Soluble Tumor Necrosis Factor-Related Apoptosis Inducing Ligand (sTRAIL) Levels to In-Stent Neointimal Hyperplasia
}

\author{
Spyridon Deftereos ${ }^{\mathrm{a}}$ Georgios Giannopoulos ${ }^{\mathrm{a}}$ Vasiliki Panagopoulou ${ }^{\mathrm{a}}$ \\ Konstantinos Raisakis ${ }^{a}$ Charalambos Kossyvakis ${ }^{a}$ Andreas Kaoukis $^{\text {a }}$ \\ Vasileios Tzalamouras ${ }^{a}$ Maria Mavri $^{\text {a }}$ Vlasios Pyrgakis $^{\text {a }}$ Michael W. Cleman $^{c}$ \\ Christodoulos Stefanadis ${ }^{\mathrm{b}}$ \\ ${ }^{a}$ Cardiology Department and Cardiac Catheterization Laboratory, Athens General Hospital 'G. Gennimatas', and \\ b 1st Department of Cardiology, University of Athens Medical School, Hippokration Hospital, Athens, Greece; \\ 'Section of Cardiovascular Medicine, Yale University School of Medicine, New Haven, Conn., USA
}

For editorial comment see p. 94

\section{Key Words}

Apoptosis $\cdot$ sTRAIL $\cdot$ In-stent restenosis $\cdot$ Intravascular

ultrasound $\cdot$ Neointima

\begin{abstract}
Objectives: Soluble tumor necrosis factor-related apoptosis inducing ligand (sTRAIL) has been shown to exert protective action against atherosclerosis. The aim of this study was to investigate potential associations of coronary sTRAIL levels with indices of in-stent neointimal hyperplasia. Methods: 67 patients who underwent percutaneous coronary intervention with drug-eluting stent were followed up at approximately 12 months with determination of coronary sTRAIL concentration, angiography and intravascular ultrasound evaluation of the stent sites. Results: Mean sTRAIL concentration was $72.2 \pm 2.8 \mathrm{pg} / \mathrm{ml}$. sTRAIL was negatively correlated to indices of neointimal hyperplasia and positively correlated to in-stent minimum lumen area $(p<0.001)$. Neointimal obstruction and maximal in-stent cross-sectional neointima burden in patients in the upper sTRAIL quartile
\end{abstract}

were $3.8 \pm 1.2$ and $12.6 \pm 3.3 \%$, respectively, versus 14.0 \pm 0.7 and $49.8 \pm 2.7 \%$ in the lower quartile $(p<0.001$ for both). sTRAIL levels were significantly lower in patients with binary restenosis ( $48.7 \pm 3.0 \mathrm{vs}$. $75.2 \pm 2.9 \mathrm{pg} / \mathrm{ml} ; \mathrm{p}<0.001)$. In the multivariate analysis, sTRAIL was an independent predictor of neointimal hyperplasia. Conclusion: This study demonstrates a negative association of sTRAIL to in-stent neointima formation. The potential pathophysiologic substrate of this effect implicates modulation of apoptosis in various cell types. These observations should prompt further evaluation of the link between STRAIL and in-stent restenosis.

Copyright $\odot 2012$ S. Karger AG, Basel

\section{Introduction}

Neointimal hyperplasia is known to play a dominant role in the pathogenesis of in-stent restenosis following percutaneous coronary interventions (PCI) with stent implantation [1]. There seems to be a delicate balance between

\section{KARGER}

Fax +4161306 1234

E-Mail karger@karger.ch

www.karger.com (c) 2012 S. Karger AG, Basel

$0008-6312 / 12 / 1232-0097 \$ 38.00 / 0$

Accessible online at:

www.karger.com/crd
Georgios Giannopoulos, MD

Cardiology Department, Athens General Hospital 'G. Gennimatas'

154 Mesogeion Avenue

GR-11527 Athens (Greece)

E-Mail ggiann@med.uoa.gr 
cell proliferation and apoptosis in vascular smooth muscle cells, with apoptosis signaling molecules being implicated in the regulation of vascular cell proliferation and, thus, linked to the processes leading to atherosclerotic plaque development [2]. Apoptotic indices have been linked to the degree of in-stent restenosis in vivo in patients following PCI [3]. The tumor necrosis factor (TNF)-related apoptosis inducing ligand (TRAIL) is a protein, member of the TNF ligand superfamily, which can be secreted as a vesicle-associated form [4] or a soluble form $[5,6]$. The exact mechanisms underlying the role of soluble TRAIL (sTRAIL) in the process of coronary atherosclerosis are uncertain, since downstream signaling, following binding of sTRAIL to receptors on human vascular muscle and endothelial cells, has been shown to lead both to apoptosis [7] and promotion of cell survival $[8,9]$. However, most evidence from experimental [10] and clinical [11] studies indicate that sTRAIL may play a protective role against atherosclerosis, although there is also evidence to the contrary [11].

The principal aim of the present study was to measure coronary sTRAIL levels in patients with previous PCI and investigate potential associations with intravascular ultrasound (IVUS)-derived parameters of in-stent neointimal hyperplasia.

\section{Methods}

\section{Population}

This was a cross-sectional, one-group study. Patients with previous PCI with drug-eluting stent(s) underwent follow-up angiography with IVUS evaluation of all implanted stents 1014 months after stent implantation. Exclusion criteria were: acute coronary syndrome, calculated creatinine clearance $<30$ $\mathrm{ml} / \mathrm{h} / 1.73 \mathrm{~m}^{2}$, left ventricular ejection fraction $<40 \%$, coronary anatomy unfavorable for IVUS study (excessive tortuosity, steep take-off angle of the target vessel), discontinuation of both antiplatelet agents (aspirin and clopidogrel) or statin during the time elapsed from the index PCI. The angiogram-IVUS study was performed regardless of symptoms after obtaining written informed consent from all patients. The study was approved by the institutional review board and was implemented according to the provisions of the Declaration of Helsinki.

\section{Procedures}

Left cardiac catheterization was performed through the transradial or the transfemoral route. Immediately after cannulation of each coronary artery (left main and right coronary artery) blood was drawn through the angiography catheter. sTRAIL was measured using a commercially available enzyme immunoassay kit (R\&D Systems, Minneapolis, Minn., USA) according to the manufacturer's instructions in a certified research laboratory. The assay sensitivity is $0.57-7.87 \mathrm{pg} / \mathrm{ml}$ (minimum detectable concentration $2.86 \mathrm{pg} / \mathrm{ml}$ ).
Standard coronary angiography followed. IVUS was used to study all implanted stents. After intracoronary administration of $0.3 \mathrm{mg}$ nitroglycerin, a digital IVUS catheter (Eagle Eye ${ }^{\circledR}$ Gold, Volcano Co., Rancho Cordova, Calif., USA) was introduced into the target vessel and a pullback was performed through the implanted stent, with a motorized automatic pullback system (Track Back ${ }^{\circledR}$ II, Volcano Co.) at a constant speed of $0.5 \mathrm{~mm} / \mathrm{s}$.

Captured data were analyzed off-line on an $5^{\mathrm{TM}}$ Imaging System workstation (Volcano Co.). Each recorded pullback loop was inspected by formally trained IVUS operators (certified by official IVUS-training teaching centers), who made manual corrections to the automated border delineation applied by the system software. Volumetric plaque data were then automatically calculated. Neointima volume was calculated as stent minus lumen volume and divided by the stent length in millimeters to account for different stent lengths (volume index - VI). Percent neointimal obstruction was defined as neointimal volume divided by stent volume. Cross-sectional neointimal burden (CNB, \%) was defined as the neointimal area divided by stent area. Maximal instent CNB equal to or greater than $60 \%$ was considered as IVUSdefined binary in-stent restenosis [12]. In-stent minimum lumen area (MLA) was also measured and recorded. A subset of the pullbacks (approximately 20\%) was analyzed twice, unbeknownst to the reviewers. The intra-observer correlation index was 0.90 for lumen measurements and 0.87 for plaque volumes.

\section{Statistical Analysis}

Data analysis was performed per implanted stent. Each artery where a pullback was performed was matched to the sTRAIL concentration measured in the blood drawn from the left main (for stents in the left anterior descending and left circumflex artery) or the right coronary artery. Continuous variables were expressed as mean \pm standard error of the mean (SEM), unless otherwise indicated. If their distribution deviated significantly from normal, nonparametric tests were applied. Categorical variables were expressed as percentages and counts and compared using the $\chi^{2}$ test or Fisher's exact test. Multivariate analysis of variance (MANOVA) was applied to test associations to in-stent neointimal hyperplasia indices (neointima VI, neointimal obstruction, MLA and CNB). The variables which were univariately associated to these indices were entered as independent parameters in the model. Predictors of binary restenosis were tested using binary logistic regression analysis. IBM ${ }^{\circledR}$ SPSS ${ }^{\circledR}$ Statistics 19.0 software package was used (SPSS Inc., Chicago, Ill., USA). Two-sided p values $<0.05$ were considered to be significant.

\section{Results}

One hundred and three stented arterial segments were studied in 67 patients (44 male; aged $65.1 \pm 0.9$ ), satisfying the criteria outlined in Methods. The basic characteristics are summarized in table 1.

Mean coronary sTRAIL concentration was $72.2 \pm 2.8$ $\mathrm{pg} / \mathrm{ml}$. It did not show significant variation with gender $(\mathrm{p}=0.856)$, but was significantly, although weakly, correlated to age $(\mathrm{r}=-0.38, \mathrm{p}<0.001)$ and left ventricular 
ejection fraction $(\mathrm{r}=0.52, \mathrm{p}<0.001)$. sTRAIL was lower in diabetics $(60.5 \pm 2.6$ vs. $86.1 \pm 4.5 \mathrm{pg} / \mathrm{ml} ; \mathrm{p}<0.001)$. Current smoking, hypertension and dyslipidemia were not significantly associated with sTRAIL levels.

\section{In-Stent Neointimal Hyperplasia and Restenosis Indices}

In-stent neointima VI, neointimal obstruction, maximal in-stent CNB and in-stent MLA are summarized in table 1. Exploration of potential univariate associations of these indices to basic demographic and risk characteristics revealed the following significant relations. Neointimal VI was higher in men than women $(0.9 \pm 0.1$ vs. 0.6 $\pm 0.1 \mathrm{~mm}^{3} ; \mathrm{p}=0.036$ ), while the other three indices were not correlated to gender. Diabetes was a significant factor for all four indices, with neointima VI $(1.0 \pm 0.1$ vs. 0.7 $\left.\pm 0.1 \mathrm{~mm}^{3} / \mathrm{mm} ; \mathrm{p}=0.030\right)$, neointima obstruction ( 10.0 vs. $6.4 \% ; \mathrm{p}=0.002)$ and $\mathrm{CNB}(40 \pm 3$ vs. $21 \pm 3 \%$; $<<$ 0.001 ) being higher in diabetics, while MLA was lower in diabetic patients $\left(5.0 \pm 0.1\right.$ vs. $\left.5.7 \pm 0.1 \mathrm{~mm}^{2} ; \mathrm{p}<0.001\right)$. Stent type was, as expected, significantly associated with neointima formation. Neointima VI, neointimal obstruction and maximal in-stent CNB were lower with sirolimus-eluting stents versus paclitaxel $(0.3 \pm 0.0$ vs. 1.4 $\pm 0.1 \mathrm{~mm}^{3} / \mathrm{mm}, 3.5 \pm 0.3$ vs. $13.5 \pm 0.6 \%, 18 \pm 2.5$ vs. $46 \pm 2.0 \%$, respectively; $\mathrm{p}<0.001$ for all). Correspondingly, MLA was higher with sirolimus-eluting stents (5.8 \pm 0.1 vs. $\left.4.8 \pm 0.1 \mathrm{~mm}^{2} ; \mathrm{p}<0.001\right)$; of note, sTRAIL concentration was also higher in patients with sirolimuseluting stents $(89.3 \pm 3.7$ vs. $54.0 \pm 2.3 \mathrm{pg} / \mathrm{ml} ; \mathrm{p}<0.001)$. In addition, age was positively correlated to neointima VI $(\mathrm{p}=0.002)$ and neointimal obstruction $(\mathrm{p}=0.022)$ and inversely correlated to MLA ( $\mathrm{p}=0.003$; Spearman's rho $0.30,0.23$ and -0.30 , respectively). Left ventricular ejection fraction was inversely correlated to neointima VI $(\mathrm{p}<0.001)$, neointimal obstruction $(\mathrm{p}<0.001)$ and maximal in-stent CNB ( $\mathrm{p}<0.001)$, and positively correlated to MLA ( $\mathrm{p}<0.001$; Spearman's rho $-0.66,-0.66,-0.68$ and 0.64 , respectively). Stent nominal diameter was also an important univariate factor, positively correlated to neointima VI ( $\mathrm{p}<0.001)$, neointimal obstruction ( $\mathrm{p}<$ $0.001)$ and maximal in-stent CNB $(\mathrm{p}<0.001)$, and inversely correlated to MLA ( $\mathrm{p}<0.001$; Spearman's rho $0.55,0.56,0.57$ and -0.37 , respectively).

Stent nominal diameter and stent length, as well as left ventricular ejection fraction were associated to the presence of binary restenosis ( $\mathrm{p}<0.01$ for all). The proportion of men among patients with restenosis was higher (83\%), compared to $64 \%$ among those without binary restenosis, without reaching statistical significance $(p=0.214)$. Dia-
Table 1. Basic population characteristics and coronary imaging findings

\begin{tabular}{lc}
\hline & $\begin{array}{c}\text { Patients } \\
(\mathrm{n}=67)\end{array}$ \\
\hline Male gender & $44(66)$ \\
Age, years & $65.1 \pm 0.9$ \\
Diabetes mellitus & $29(43)$ \\
Hypertension & $34(51)$ \\
Dyslipidemia & $34(51)$ \\
Current smoking & $27(40)$ \\
LVEF, \% & $57 \pm 0.6$ \\
\hline & \\
& Stented arterial \\
& segments $(\mathrm{n}=103)$ \\
\hline Coronary artery & \\
$\quad$ Left anterior descending artery & $44(66)$ \\
$\quad$ Left circumflex artery & $10(15)$ \\
$\quad$ Right coronary artery & $13(19)$ \\
Drug-eluting stent type & \\
$\quad$ Sirolimus & $53(52)$ \\
Paclitaxel & $50(49)$ \\
Stent length, mm & $27.6 \pm 0.4$ \\
Stent nominal diameter, mm & $3.3 \pm 0.04$ \\
Neointima VI, mm ${ }^{3} /$ mm & $0.8 \pm 0.06$ \\
Minimum lumen area, mm ${ }^{2}$ & $5.3 \pm 0.09$ \\
Neointima obstruction, \% & $8.3 \pm 0.6$ \\
Cross-sectional neointima burden, $\%$ & $31 \pm 2.1$ \\
sTRAIL, pg/ml & $72 \pm 2.8$ \\
Binary restenosis & $12(11.7)$ \\
& \\
& \\
& \\
& \\
&
\end{tabular}

Continuous variables are expressed as mean 8 SEM and categorical variables as count with the percentage in parentheses.

LVEF = Left ventricular ejection fraction.

betes, on the other hand, was significantly more frequent among those with restenosis $(\mathrm{p}<0.001)$. Paclitaxel-eluting stent, although associated with more marked in-stent neointima formation, as described in the previous paragraph, was not significantly correlated to binary restenosis $(\mathrm{p}=0.470)$.

Coronary sTRAIL appeared to be protective against in-stent neointimal growth, exhibiting negative correlation to indices of neointimal hyperplasia and positive correlation to MLA ( $\mathrm{p}<0.001$ for all; fig. 1). The associations between sTRAIL and neointimal obstruction as well as between sTRAIL and in-stent CNB exhibited a similar significant trend (neointimal obstruction and maximal in-stent CNB of patients in the upper sTRAIL quartile were $3.8 \pm 1.2$ and $12.6 \pm 3.3 \%$, respectively, vs. $14.0 \pm 0.7$ and $49.8 \pm 2.7 \%$ in the lower sTRAIL quartile; 

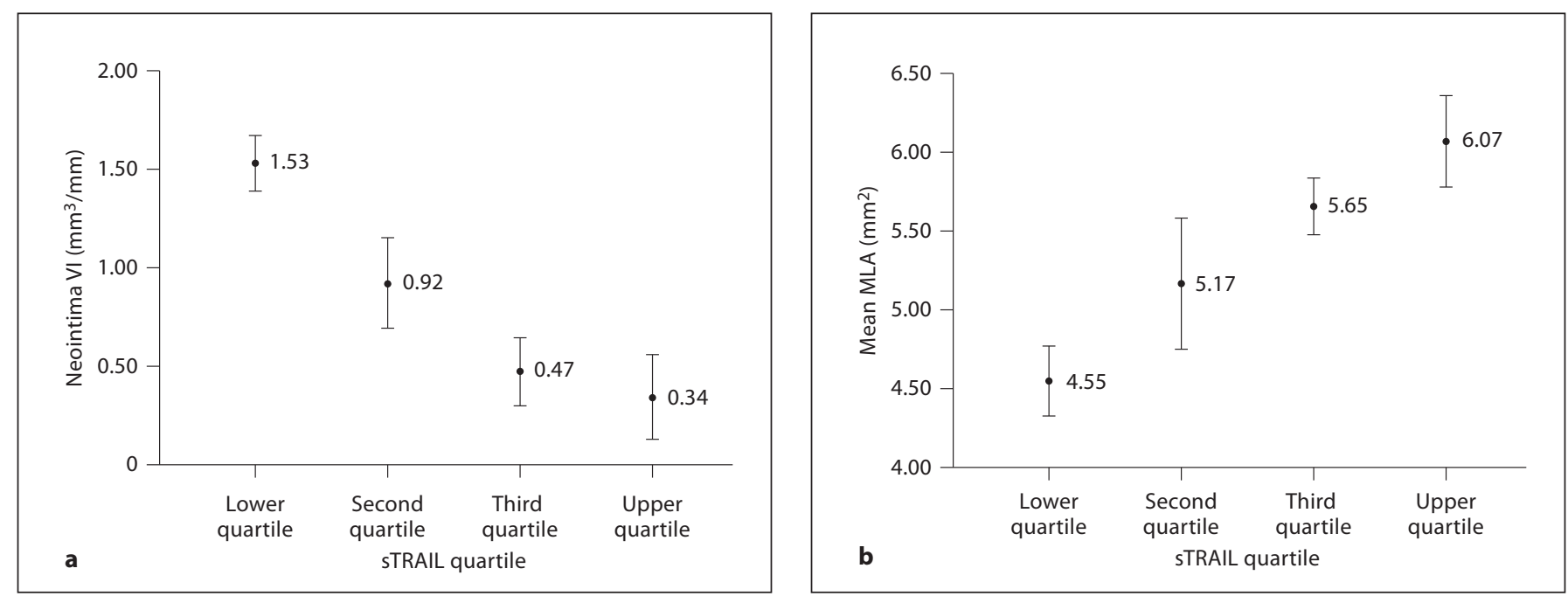

Fig. 1. Mean values (with 95\% confidence intervals) of in-stent neointima VI (a) and MLA (b) in each quartile of sTRAIL concentration.

Table 2. Results of multivariate analysis of variance test (Wilks' lambda)

\begin{tabular}{llr}
\hline Variables & Wilks' lambda & \multicolumn{1}{c}{$\mathrm{p}$} \\
\hline Age & 0.91 & 0.071 \\
Gender & 0.91 & 0.069 \\
Stent diameter & 0.71 & $<\mathbf{0 . 0 0 1}$ \\
LVEF & 0.94 & 0.256 \\
sTRAIL & 0.81 & $<\mathbf{0 . 0 0 1}$ \\
Diabetes mellitus & 0.86 & $<\mathbf{0 . 0 0 9}$ \\
Stent type (PES or SES) & 0.52 & $<\mathbf{0 . 0 0 1}$ \\
\hline
\end{tabular}

All variables univariately associated to in-stent neointima volume index, neointimal obstruction, in-stent minimum lumen area and in-stent cross-sectional neointima burden (dependent variables) were entered as independent variables.

LVEF = Left ventricular ejection fraction; PES = paclitaxeleluting stent; SES = sirolismus-eluting stent.

$\mathrm{p}<0.001$ for all). In regard to in-stent binary restenosis, sTRAIL levels were significantly lower in patients with restenosis $(48.7 \pm 3.0$ vs. $75.2 \pm 2.9 \mathrm{pg} / \mathrm{ml} ; \mathrm{p}<0.001)$.

\section{Multivariate Analysis}

In the MANOVA performed to test for independent associations with neointimal hyperplasia indices, neointima VI, neointimal obstruction, MLA and CNB were entered as dependent variables and age, gender, left ventricular ejection fraction, stent type, stent diameter, dia- betes and sTRAIL level were the independent variables (univariate correlates of neointima formation). The results (table 2) clearly denote that the stent type and diameter, diabetes mellitus and sTRAIL levels were independent predictors of the four in-stent neointimal hyperplasia parameters.

\section{Discussion}

The findings of the present study suggest a protective role of coronary artery sTRAIL against in-stent neointimal hyperplasia, as it was shown that coronary artery sTRAIL levels are inversely correlated to IVUS-derived markers of neointima formation. This was true for all four measured indices of in-stent neointimal hyperplasia. sTRAIL levels were found to be independently correlated to these parameters in the multivariate analysis, which suggests a link - in fact a strong negative association between sTRAIL and in-stent neointima formation.

These results are in keeping with previous experimental and clinical reports of an inverse association of sTRAIL levels to atherosclerotic disease, both in experimental and clinical studies [10,13-16]. However, some of these studies have yielded contradicting results in regard to specific aspects of the role of sTRAIL in atherosclerotic processes. In particular, while Watt et al. [10] showed a link between TRAIL deficiency and markedly increased atheromatous burden, they did not find significant differences in plaque composition. On the other hand, Di 
Bartolo et al. [16] observed clear signs of increased plaque vulnerability in TRAIL-deficient mice: thinner fibrous cap, more extensive necrotic cores and macrophage infiltration. The differences might be attributed to different diet fat contents between the two studies. These inconsistencies between observations underscore the multiplicity of interactions between TRAIL and various inborn and environmental factors, which render the investigation of its role in atheromatosis an onerous task, subject to several potential influences and confounders. Our group has shown that sTRAIL levels are inversely associated to IVUS-defined coronary atheromatosis burden, as well as to the quantity of necrolipidic plaque content (using IVUS-virtual histology) [17]. TRAIL is a member of the TNF superfamily $[18,19]$. sTRAIL acts on various cellular constituents of the vascular wall, including the endothelium and smooth muscle cells [13], through the Akt and extracellular signal-regulated kinase pathways [8]. In addition, it promotes endothelial production of nitric oxide and prostanoid derivatives [20] and has been shown to be reduced in patients with acute coronary syndromes [13]. Accordingly, Secchiero et al. [21] have shown that sTRAIL is reduced in patients with acute myocardial infarction.

Of note, although existing evidence regarding the role of sTRAIL in atherosclerosis pertains mainly to primary atherosclerotic processes, a relationship with restenosis after PCI has been suggested in an interesting report by Satoh et al. [22], where sTRAIL was found to be negatively associated with angiographic restenosis: sTRAIL levels after PCI were significantly increased in the non-restenosis group and sTRAIL levels were related to soluble vascular cell adhesion molecule- 1 and soluble E-selectin. In addition, Watt et al. [10] showed that TRAIL-deficient mice had higher levels of smooth muscle cell activation and larger early atherosclerotic lesions compared to nonTRAIL-deficient mice. Furthermore, sTRAIL inhibits mediators of the Akt pathway $[8,10]$, which has been implicated in vascular restenosis after balloon injury and stenting [23]. On the other hand, in a contradicting report by Chan et al. [11], increased TRAIL expression has been linked to vascular smooth muscle cell proliferation and neointima formation after arterial injury. However, the weight of evidence in various settings of atherosclerotic artery disease, as already mentioned, points toward a protective effect of sTRAIL against atherosclerosis $[10,13-17$, 21]. This theoretical framework is substantiated in vivo by our present observation, that coronary artery sTRAIL is inversely correlated to several indices of in-stent neointima hyperplasia.

\section{Study Limitations}

IVUS image analysis was performed by certified IVUS operators, who interpret a substantial number of IVUS studies on a monthly basis, but not in a separate core laboratory. This could be a source of bias, although it should be noted that IVUS image interpretation was performed in a blinded manner. The invasive nature of the present study (coronary angiography and IVUS) precluded the inclusion of a larger number of subjects, which made the assessment of clinical outcomes, such as ischemia-driven revascularization of the target lesion, statistically implausible.

\section{Conclusion}

The present study demonstrates an inverse association of sTRAIL to in-stent neointima formation. The results imply that this association may be biologically relevant in vivo, although its true clinical significance is unclear. We believe that the presented observations should prompt further evaluation of the link between sTRAIL and instent restenosis, which may deepen our knowledge regarding the relation between apoptotic processes and instent neointima formation.

\section{Conflict of Interest}

None.

References $>_{1}$ Hoffmann R, Mintz GS, Dussaillant GR, Popma JJ, Pichard AD, Satler LF, Kent KM, Griffin J, Leon MB: Patterns and mechanisms of in-stent restenosis: a serial intravascular ultrasound study. Circulation 1996;94: 1247-1254.

2 Cai W, Devaux B, Schaper W, Schaper J: The role of Fas/APO-1 and apoptosis in the development of human atherosclerotic lesions. Atherosclerosis 1997;131:177-186.

- 3 Deftereos S, Giannopoulos G, Kossyvakis C, Kaoukis A, Raisakis K, Driva M, Panagopoulou V, Lappos S, Rentoukas I, Pyrgakis V, Alpert MA: Effect of quinapril on in-stent restenosis and relation to plasma apoptosis signaling molecules. Am J Cardiol 2010;105:54-58.

4 Monleón I, Martínez-Lorenzo MJ, Monteagudo L, Lasierra $P$, Taulés $M$, Iturralde $M$, Piñeiro A, Larrad L, Alava MA, Naval J, Anel A: Differential secretion of Fas ligand- or APO2 ligand/TNF-related apoptosis-inducing ligand-carrying microvesicles during activation-induced death of human T cells. J Immunol 2001;167:6736-6744. 
5 Mariani SM, Krammer PH: Differential regulation of TRAIL and CD95 ligand in transformed cells of the $\mathrm{T}$ and $\mathrm{B}$ lymphocyte lineage. Eur J Immunol 1998;28:973-982.

6 Daniels RA, Turley H, Kimberley FC, Liu XS, Mongkolsapaya J, Ch'En P, Xu XN, Jin BQ, Pezzella F, Screaton GR: Expression of TRAIL and TRAIL receptors in normal and malignant tissues. Cell Res 2005;15:430438.

7 Li JH, Kirkiles-Smith NC, McNiff JM, Pober JS: TRAIL induces apoptosis and inflammatory gene expression in human endothelial cells. J Immunol 2003;171:1526-1533.

-8 Secchiero P, Gonelli A, Carnevale E, Milani D, Pandolfi A, Zella D, Zauli G: TRAIL promotes the survival and proliferation of primary human vascular endothelial cells by activating the Akt and ERK pathways. Circulation 2003;107:2250-2256.

-9 Kavurma MM, Bennett MR: Expression, regulation and function of TRAIL in atherosclerosis. Biochem Pharmacol 2008;75:14411450.

10 Watt V, Chamberlain J, Steiner T, Francis S, Crossman D: TRAIL attenuates the development of atherosclerosis in apolipoprotein $\mathrm{E}$ deficient mice. Atherosclerosis 2011;215: 348-354.

-11 Chan J, Prado-Lourenco L, Khachigian LM, Bennett MR, Di Bartolo BA, Kavurma MM: TRAIL promotes VSMC proliferation and neointima formation in a FGF-2-, Sp1 phosphorylation-, and NFKB-dependent manner. Circ Res 2010;106:1061-1071.
12 Waseda K, Hasegawa T, Ako J, et al: Comparison of vascular response to zotarolimuseluting stent vs. paclitaxel-eluting stent implantation: pooled IVUS results from the ZoMaxx I and II trials. Circ J 2010;74:23342339.

13 Michowitz Y, Goldstein E, Roth A, Afek A, Abashidze A, Ben Gal Y, Keren G, George J: The involvement of tumor necrosis factorrelated apoptosis-inducing ligand (TRAIL) in atherosclerosis. J Am Coll Cardiol 2005; 45:1018-1024.

14 Mori K, Ikari Y, Jono S, Shioi A, Ishimura E, Emoto M, Inaba M, Hara K, Nishizawa Y: Association of serum TRAIL level with coronary artery disease. Thromb Res 2010;125: 322-325.

15 Secchiero P, Candido R, Corallini F, Zacchigna S, Toffoli B, Rimondi E, Fabris B, Giacca M, Zauli G: Systemic tumor necrosis factorrelated apoptosis-inducing ligand delivery shows antiatherosclerotic activity in apolipoprotein E-null diabetic mice. Circulation 2006;114:1522-1530.

16 Di Bartolo BA, Chan J, Bennett MR, Cartland S, Bao S, Tuch BE, Kavurma MM: TNFrelated apoptosis-inducing ligand (TRAIL) protects against diabetes and atherosclerosis in $\mathrm{ApoE}^{-/-}$mice. Diabetologia 2011;54:31573167.

7 Deftereos S, Giannopoulos G, Kossyvakis C, Kaoukis A, Raisakis K, Panagopoulou V, Miliou A, Theodorakis A, Driva M, Pyrgakis V, Stefanadis C, Cleman MW: Association of soluble tumour necrosis factor-related apoptosis-inducing ligand levels with coronary plaque burden and composition. Heart 2012; 98:214-218.
18 Wiley SR, Schooley K, Smolak PJ, Din WS, Huang CP, Nicholl JK, Sutherland GR, Smith TD, Rauch C, Smith CA: Identification and characterization of a new member of the TNF family that induces apoptosis. Immunity 1995;3:673-682.

19 Pitti RM, Marsters SA, Ruppert S, Donahue CJ, Moore A, Ashkenazi A: Induction of apoptosis by Apo-2 ligand, a new member of the tumor necrosis factor cytokine family. J Biol Chem 1996;271:12687-12690.

20 Zauli G, Pandolfi A, Gonelli A, Di Pietro R, Guarnieri S, Ciabattoni G, Rana R, Vitale M, Secchiero P: Tumor necrosis factor-related apoptosis-inducing ligand (TRAIL) sequentially upregulates nitric oxide and prostanoid production in primary human endothelial cells. Circ Res 2003;92:732-740.

-21 Secchiero P, Corallini F, Beltrami AP, Ceconi C, Bonasia V, Di Chiara A, Ferrari R, Zauli G: An imbalanced OPG/TRAIL ratio is associated to severe acute myocardial infarction. Atherosclerosis 2010;210:274-277.

-22 Satoh D, Inami N, Shimazu T, Kajiura T, Yamada K, Iwasaka T, Nomura S: Soluble TRAIL prevents RANTES-dependent restenosis after percutaneous coronary intervention in patients with coronary artery disease. J Thromb Thrombolysis 2010;29:471-476.

23 Deuse T, Koyanagi T, Erben RG, Hua X, Velden J, Ikeno F, Reichenspurner H, Robbins RC, Mochly-Rosen D, Schrepfer S: Sustained inhibition of epsilon protein kinase $\mathrm{C}$ inhibits vascular restenosis after balloon injury and stenting. Circulation 2010; 122:S170-S178. 